\title{
La relación núcleo-citoplasmática en la diferenciación y transformación celular del epitelio mamario
}

\author{
Ricardo Cornejo U. ${ }^{a}$ \\ 1 Departamento de Ciencias Básicas, Facultad de Medicina, Universidad de La Frontera, Temuco, Chile. \\ a Biólogo, PhD.
}

\section{RESUMEN}

Antecedentes: Las células pertenecientes a la línea $\mathrm{HC} 11$ son estimuladas tanto a proliferar mediante el Factor de Crecimiento Epidérmico, como a diferenciar estimuladas con dexametasona, insulina y prolactina, dando origen a los tipos celulares HC11 GM y HC11 IM, respectivamente. De igual manera cuando ellas son transfectadas con el oncogén ras generan Q6 GM y Q6 IM, células transformadas. Producto de ambos mecanismos estas células asumen distintas propiedades modificando tanto sus componentes como sus funciones, los cuales pueden ser cuantificados mediante técnicas morfométricas. Objetivo: Evidenciar en términos cuantitativos y morfológicos las variaciones experimentadas tanto por los núcleos como los citoplasmas y su correspondiente relación núcleo-citoplasmática $(\mathrm{N} / \mathrm{C})$ pertenecientes a células mamarias de la línea HC11 con el decorrer de los mecanismos de diferenciación y de transformación celular. Método: Se estudió a nivel de microscopia electrónica de transmisión los tipos celulares en proceso de diferenciación y transformación, cuantificando variaciones de la relación núcleo-citoplasmática y su respectiva funcionalidad. Resultados: Se evidencian diferencias estadísticamente significativas referentes a las áreas nucleares y citoplasmáticas pertenecientes a estos tipos celulares. Conclusión: Las células del epitelio mamario en proceso de diferenciación como de transformación, presentan diferentes valores en su relación N/C hecho que responde a funcionalidades específicas en cada tipo celular.

\section{PALABRAS CLAVE: Transformación celular, diferenciación celular, morfometría, relación núcleo- citoplasmática, glándula mamaria}

\section{SUMMARY}

Background: Cells of the $\mathrm{HC} 11$ line are stimulated to proliferate using the Epidermic Growth Factor, and to differentiate with dexamethasone, insulin and prolactin, giving rise to cell types $\mathrm{HC} 11 \mathrm{GM}$ and $\mathrm{HC} 11 \mathrm{IM}$, respectively. Likewise when they are transfected with the ras oncogen they generate Q6 GM and Q6 IM transformed cells. As a result of these two mechanisms, these cells assume different properties, in which both their components and their functions are modified. The modifications can be quantified by morphometric techniques. Objective: To show in quantitative and morphological terms the variations effected in both the nuclei and the cytoplasms, and the corresponding nuclear-cytoplasmic ratio of mammary cells of the $\mathrm{HC} 11$ line, under the effects of cellular differentiation and transformation mechanisms. Method: The cell types undergoing differentiation and transformation processes were studied by transmission electron microscope, permitting quantification of variations in the nuclear-cytoplasmic ratio and its relation with the respective 
functions. Results: Statistically significant differences were found in the nuclear and cytoplasmic areas of these cell types. Conclusion: cells of the mammary epithelium undergoing differentiation and transformation processes present different values for their nuclear-cytoplasmic ratio, and this responds specific functions in each cell-type.

\section{KEY WORDS: Cell differentation, cell transformation, morphometry, nucleo-cytoplasmic relation, mammary gland}

\section{INTRODUCCIÓN}

Las células pertenecientes a la línea HC11 constituye una línea de células del epitelio mamario normal, derivada del linaje COMMA 1D obtenida de glándula mamaria de ratas BALB/c en mitad de preñez, las cuales retienen características de la diferenciación normal de la glándula y producen $B$ caseína, la principal proteína de la leche (1).

Estas células reciben inducciones del Factor de Crecimiento Epidérmico y proliferan originando el tipo HC11 GM, de igual manera son estimuladas por hormonas lactogénicas y experimentan el proceso de diferenciación celular. Producto de ambos mecanismos las células sufren importantes modificaciones morfológicas y de funcionalidad.

Por otra parte, las células mamarias normales son transfectadas con el oncogén ras originando el tipo celular Q6 GM, en proceso de transformación, y posteriormente, las células franca y definitivamente transformadas corresponden al tipo Q6 IM, caracterizadas por la adquisición de propiedades neoplásicas.

Ambos tipos celulares asumen nuevas y distintas características, siendo la más importante un bloqueo total del factor de transcripción específico del gen de $B$ caseína, generando por lo tanto incapacidad para realizar esta síntesis, y por la adquisición de propiedades neoplásicas como presentar tanto mitosis consecutivas, y desrreguladas, además de una alta capacidad metastásica (2), e incentivando vías de transducción de señales involucradas en etapas de transformación maligna (3). De igual manera, se evidencian variaciones importantes de los componentes citoplasmáticos y nucleares (4).

El objetivo de este estudio es describir cuantitativamente las diferencias que pudiese experimentar la relación núcleo/citoplasmática (N/C) de los diferentes grupos celulares, y establecer relaciones con la funcionalidad específica que experimentan, determinando diferentes comportamientos que incluyen anaplasia y apoptosis (5).

\section{MATERIAL Y MÉTODO}

Microscopía Electrónica de Transmisión. Al pellet que contenía las células mamarias en mecanismos proliferativos, de diferenciación y de transformación se le adicionó solución de glutaraldehído $2 \%$, en tampón fosfato $0,15 \mathrm{M}, \mathrm{pH} 7,2$ y se mantuvo a temperatura ambiente por 2 horas. Posteriormente, fue sometido a un lavado en solución de $6 \mathrm{~g}$ de $\mathrm{NaCl}$ y $73 \mathrm{~g}$ de sacarosa, disueltos en 1 litro de agua destilada. La posfijación se realizó en solución de tetróxido de osmio al $1 \%$, disuelto en la solución de lavado antes descrita, durante una hora, a $40^{\circ} \mathrm{C}$ y acetato de uranilo al $0,5 \%$, por 18 horas. Luego de lavado el material fue deshidratado en concentraciones crecientes de acetona (30 a $100 \%$ ) e incluido en Araldita 6005 . Se obtuvieron cortes ultrafinos de aproximadamente $70 \mathrm{~nm}$ de grosor, los que fueron tratados con acetato de uranilo al $2 \%$, durante 40 minutos y citrato de plomo al $0,5 \%$, por 10 minutos. Las muestras fueron estudiadas y fotografiadas en un microscopio electrónico Phillips EM 400.

Método Estererológico. A partir de los bloques para microscopía electrónica, fueron obtenidos cortes ultrafinos, en los cuales se micrografiaron cada uno de los tipos celulares con un aumento de 10.500 $X$. Para la evaluación de las fracciones volumétricas de los diferentes componentes celulares, fue sobrepuesto un retículo de puntos en las micrografías electrónicas, y se procedió al conteo diferencial de los puntos que incidían sobre los perfiles de los componentes celulares, calculándose la fracción volumétrica que un determinado componente ocupa, mediante la siguiente ecuación (6):

Donde:

$$
F v=\frac{P i}{P t}
$$

$\mathrm{Fv}=$ fracción volumétrica del componente en estudio.

$\mathrm{Pi}=$ puntos incidentes sobre el componente en estudio. 
$\mathrm{Pt}=$ puntos totales incidentes en la estructura celular.

Con el objetivo de determinar diferencias estadísticamente significativas los datos morfométricos obtenidos fueron sometidos a la prueba de Wilcoxon para muestras no paramétricas.

\section{RESULTADOS}

En las micrografías electrónicas obtenidas de los tipos celulares proliferantes (Figura 1), diferenciados (Figura 2), transfectados (Figura 3) y transformados (Figura 4), se realizaron los análisis morfométricos correspondientes. Los valores obtenidos determinan diferencias estadísticamente significativas $(p=0,043)$. Teniendo en cuenta que la prueba de Wilcoxon establece diferencias con un valor de $Z=2,023$ tanto para las áreas que poseen los núcleos como los citoplasmas, y por ende en su relación N/C evaluados en los tipos celulares descritos, indican que efectivamente existen diferencias estadísticamente significativas, situación que permite constatar claramente que en medida que transcurren el mecanismo de diferenciación ella experimenta una marcada disminución, mientras que en procesos de transformación la relación N/C aumenta (Figura 5).

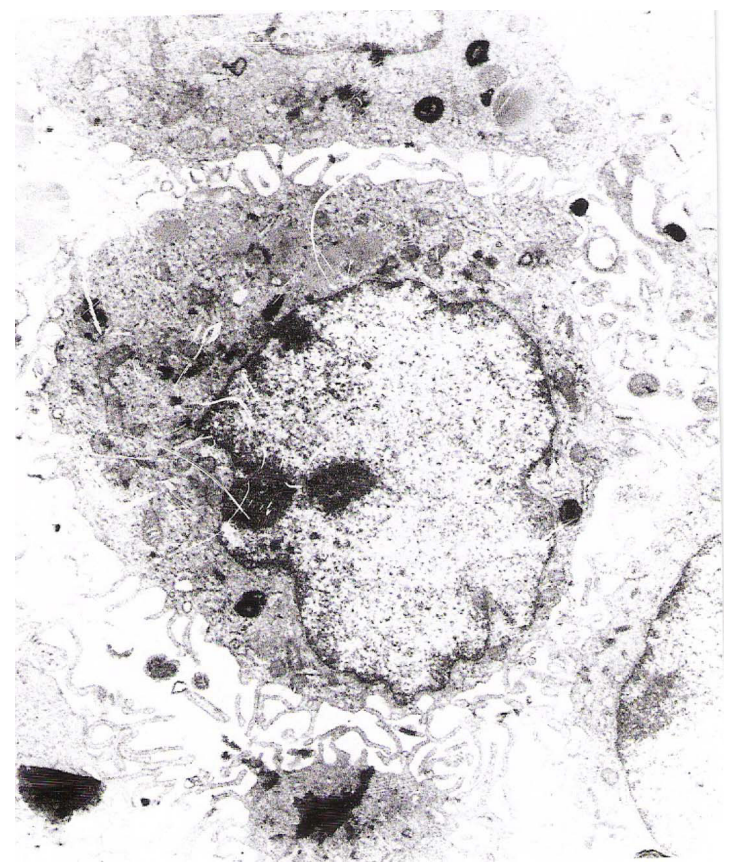

Figura 1. Micrografía electrónica de célula proliferante HC11 GM perteneciente a glándula mamaria. $10.500 \mathrm{X}$

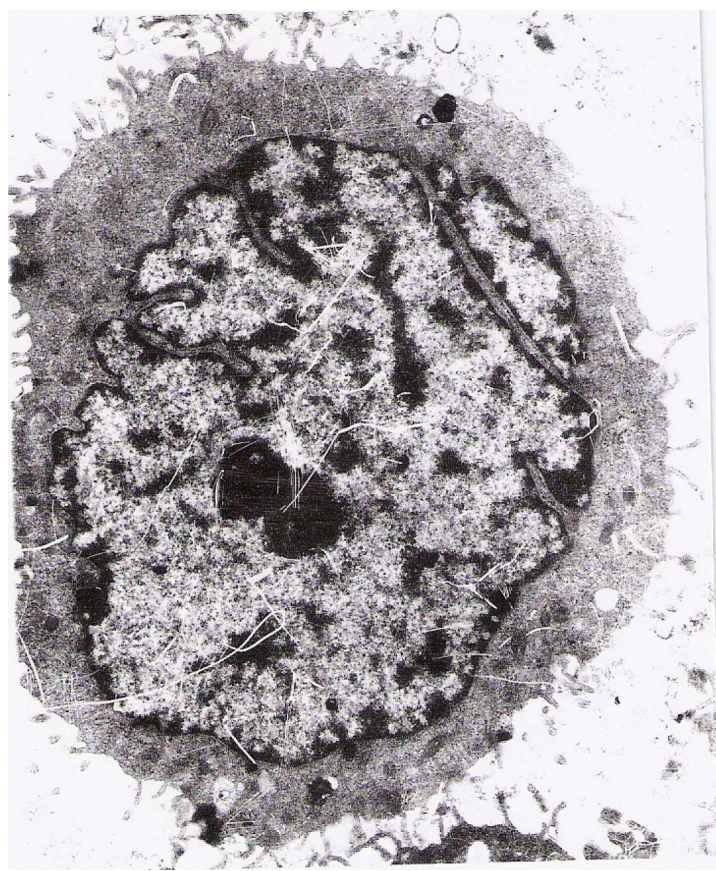

Figura 2. Micrografía electrónica perteneciente a célula diferenciada HC11 IM perteneciente a glándula mamaria. $10.500 \mathrm{X}$.

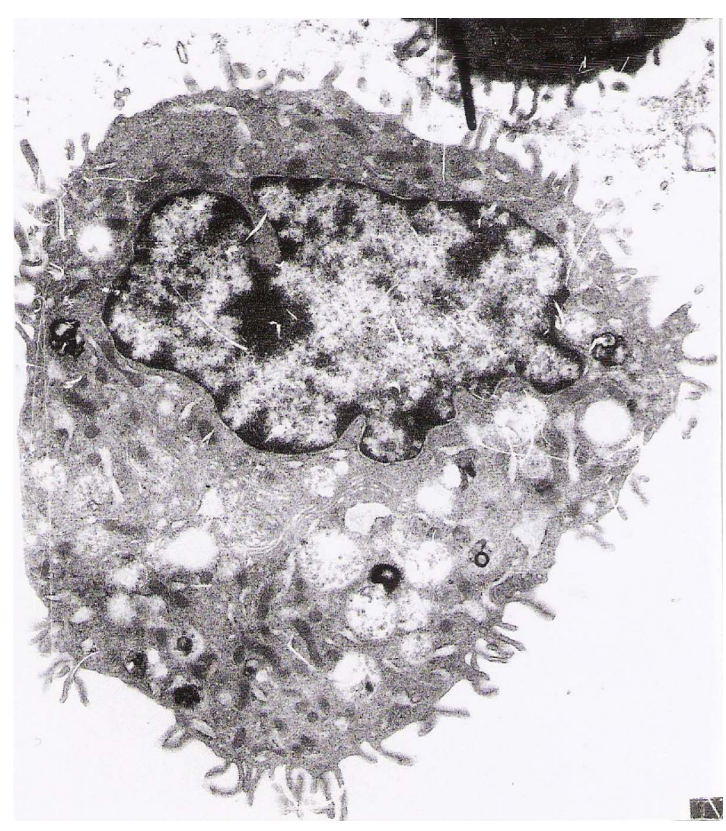

Figura 3. Micrografía electrónica perteneciente a célula transfectada Q6 GM perteneciente a glándula mamaria. $10.500 \mathrm{X}$. 


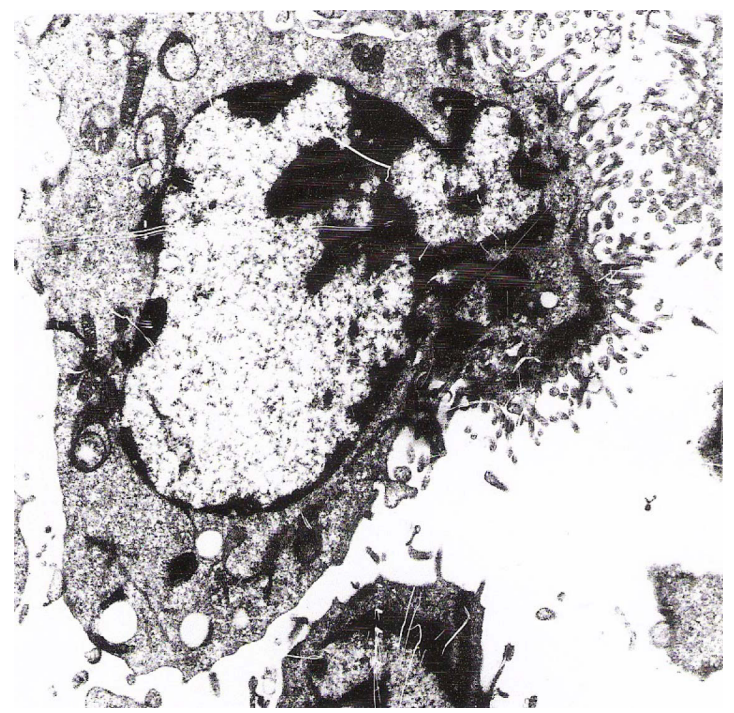

Figura 4. Micrografía electrónica perteneciente a célula transformada Q6 IM perteneciente a glándula mamaria. $10.500 \mathrm{X}$

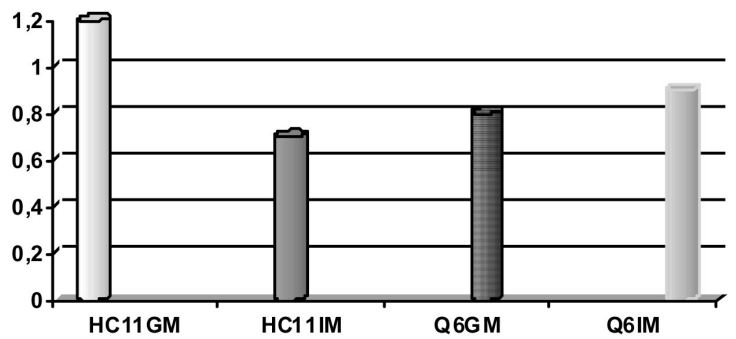

Figura 5. Relación N/C evaluada mediante técnicas morfométricas en los tipos celulares proliferantes, diferenciados, transfectados y transformados pertenecientes al epitelio mamario.

\section{DISCUSIÓN}

La relación núcleo-citoplasmática de la célula diferenciada con respecto a la proliferante es menor como se muestra en la Figura 5, y sería consecuencia tanto de una notable disminución relativa del núcleo como de un aumento proporcional del citoplasma. Esta observación es coincidente con lo descrito en 1975 por Junqueira y Salles (7) en relación a la morfología de las células en proceso de diferenciación.

Sin duda que, tanto la disminución del tamaño nuclear como del aumento del volumen citoplasmático constituyen una respuesta a las estimulaciones de las hormonas lactogénicas, siendo probable que tanto dexametasona como prolactina tengan una importante función en la diferenciación, considerando su funcionalidad como hormonas anabólicas traducido en inducciones para proliferación y crecimiento celular.

En este contexto, el hecho que dexametasona sea capaz de promover diferenciación celular y que posea la misma constitución química esteroidal característica de estrógenos, los cuales inducen un gran número de enzimas involucradas en síntesis de ADN, como igualmente aumentando la transcripción de varios genes y por consiguiente sintetizando variadas proteínas que desencadenan una serie de eventos específicos de la estimulación hormonal, habla a favor de que estrógenos y dexametasona tengan una acción semejante en la promoción de la diferenciación celular (8).

De igual manera, estos datos son coincidentes con la reducción de volumen nuclear y aumento de citoplasma observadas en el epitelio vaginal de ratas de la línea Balb-c tratados con estrógenos (9), y de igual forma en la disminución de la relación núcleo-citoplasmática observada en el epitelio vaginal de ratas inducidas por estrógenos (10).

Por otra parte, en los mecanismos tanto de transfección como de transformación celular se evidencia un ligero aumento de la relación N/C, constatándose un mayor incremento en el volumen presentados por el núcleo de Q6 IM, recordando que el hecho de poseer escaso citoplasma es una característica de las células en activos procesos de proliferación, como acontece en estas células francamente neoplásicas que experimentan mitosis consecutivas y desrreguladas (11).

Este hallazgo en el aumento de la relación N/C de células en proceso anaplásico, es coincidente con los resultados enunciados por Borja y Franco (12), los cuales describen un importante aumento de esta variable en células cervicales cancerosas de mujeres. De igual manera, otros autores (13) comunican este aumento en la relación N/C observada en células neoplásicas glandulares de epitelio cervical. Finalmente, nuestros resultados son semejantes a los entregados por Roque y cols (14), quienes determinan un acentuado aumento de esta variable en células pertenecientes a carcinoma de glándula mamaria de caninos.

\section{CONCLUSIÓN}

Las células mamarias en proceso de diferenciación se caracterizan por una notable disminución de la relación núcleo-citoplasmática, demostrándose que en los mecanismos de transformación neoplásica las células mamarias presentan un au- 
mento progresivo de esta variable. La relación N/C puede indicarse como un marcador tanto de diferenciación como de transformación celular en este sistema biológico.

\section{REFERENCIAS}

1. Ball R, Friis R, Schoenenberger C, Doppler W, Groner B. Prolactin regulation of beta-casein gene expression and of a cytosolic $120 \mathrm{kD}$ protein in a cloned mouse mammary epithelial cell line. EMBO J 1988;7:2089-95.

2. Schlatter B, Waghorne C. Persistence of Ha-ras- induced metastatic potential of SPI mammary tumors despite loss of the Ha-ras shuttle vector. Proc Natl Acad Sci USA 1992;89:9986-90.

3. Reuther GW, Der CJ. The ras branch of small GTPases: ras family members don't fall far from the tree. Curr Op Cell Biol. 2000;12:157-65.

4. Happ B, Hynes N, Groner B. Ha-ras and v-raf oncogenes, but not int-2 and c-myc interfere with the lactogenic hormone dependent activation of the mammary gland specific transcription factor. Cell Growth Differ 1993;4:9-15.

5. Cornejo R. Apoptosis en células mamarias transfectadas con el oncogen ras. Rev Chil Obstet Ginecol 2007;72:362-5.

6. Weibel ER. Stereological principes for morphometry in electron microscopic cytology. Int Rev Cytol 1969;26:235-302.
7. Junqueira $L$, Salles L. Ultra-estrutura e funçao celular. Rio de Janeiro, Editorial Guanabara-Koogan, 121 pp, 1975.

8. Chaudhuri P, Walker M, Beattie C, Das Gupta T. Endocrines correlates of human malignat melanoma. J Surg Res 1979;26:214-9.

9. Cooper R, Cardiff R, Wellings $S$. Ultrastructure of vaginal keratinization in estrogen treated inmature Balb/ cCRGL mice. Z Zellforsch Mikrosk Anat 1967;77:377403.

10. Caldini E. Estudo morfométrico dos efeitos da administraçao de esteroides ováricos sobre os componentes celulares do epitelio vaginal de ratas castradas. Tese Mestrado 1987; Universidade de Sao Paulo, 113 p.

11. Barbacid M. Human oncogenes. In: De Vita J, Hellmans S, Rosenberg S. Important advances in oncology. Philadelphia, JB Lippincott 1986;3-32.

12. Borja G, Franco D. Factores de riesgo que pronostican hallazgo de citologías cervicales anormales en poblaciones de mujeres de obreros. SISBID 2000;1-7.

13. Grases P, Tressera F, Lopez L. Cuello uterino: atipias y lesiones premalignas no invasoras. Rev Obstet Ginecol Venez 2005;65:25-30.

14. Roque A, Ochoa J, Narvaez J. Carcinoma de glandula mamaria de canino. Condrosarcoma mesenquimal sinonasal grado tres y carcinosarcoma de glándula mamaria de un canino. Estudio clínico e histopatológico. Int J Morphol 2008;26:861-75. 